\title{
OTIMIZAÇÃO DO USO DA ÁGUA NO PERÍMETRO IRRIGADO DO GORUTUBA, UTILIZANDO-SE A TÉCNICA DA PROGRAMAÇÃO LINEAR ${ }^{1}$
}

\author{
Daniel Fonseca de Carvalho², Antônio Alves Soares ${ }^{3}$, Carlos Antônio Alvares Soares Ribeiro ${ }^{4}$, \\ Gilberto C. Sediyama ${ }^{3}$ \& Fernando Falco Pruski ${ }^{3}$
}

\begin{abstract}
RESUMO
Com este trabalho, objetivou-se selecionar as culturas e os meses de plantio que proporcionem a maximização da renda do agricultor e da utilização de recursos hídricos no Perímetro Irrigado do Gorutuba, utilizando-se um modelo de programação linear cuja função-objetivo visa maximizar as receitas líquidas mensais em função da área cultivada com as culturas normalmente utilizadas na região, tendo-se como restrição a área irrigável do lote e a quantidade de água disponível. A diferença observada entre as receitas líquidas obtidas na otimização, com e sem restrição de área por cultura, foi de $15,2 \%$ nos lotes empresariais e de $10,2 \%$ nos demais lotes. O sistema de distribuição de água não limita a escolha das culturas a serem implantadas no projeto Gorutuba, mas a diferença entre a ocupação das áreas irrigadas e, conseqüentemente, as receitas líquidas observadas, foram mais influenciadas pelos sistemas de irrigação utilizados que pelas variações na capacidade de retenção de água dos solos considerados.
\end{abstract}

Palavras-chave: otimização, irrigação, programação linear
OPTIMIZATION OF WATER USE IN THE GORUTUBA IRRIGATION DISTRICT, MINAS GERAIS (BRAZIL) USING THE LINEAR PROGRAMMING MODEL

\begin{abstract}
This research was developed with the objective of selecting the crops and planting dates in order to maximize the farmers income and the water resources in the Gorutuba Irrigation District. A linear programming model was used with an objective function to maximize the monthly income as a function of the cultivated area with the crops used in the region, subjected to the restrictions of the irrigated area and the availability of water. The net income differences obtained in the optimization with and without restriction in the cultivated area of yearly crops were $15.2 \%$ and $10.2 \%$, for the large and the small farm plots, respectively. The water distribution system does not limit the crop selection in the irrigation district. The difference in the net income caused by the crops used was influenced more by the type of irrigation systems than by the soil water holding capacity.
\end{abstract}

Key words: optimization, irrigation, linear programming

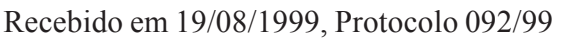

${ }^{1}$ Parte da tese do primeiro autor, apresentada à UFV para a obtenção do título de Doutor em Engenharia Agrícola

${ }^{2}$ Prof. Adjunto, Depto. de Engenharia/UFRRJ. CEP 23851 - 970. Seropédica, RJ. Fone: (0xx21) 682 1865. E-mail: carvalho@ufrrj.br

${ }^{3}$ Prof. Titular, Departamento de Engenharia Agrícola, UFV, Viçosa, MG. Fone: (0xx31) 8992734

${ }^{4}$ Prof. Adjunto, Depto. de Engenharia Florestal, UFV, Viçosa, MG
} 


\section{INTRODUÇÃO}

A irrigação é uma técnica alternativa que visa ao aumento da produtividade das culturas, especialmente em regiões áridas e semi-áridas; esta técnica, entretanto, apresenta grande impacto nas disponibilidades hídricas dos mananciais d'água, devido ao grande consumo de água requerido nos sistemas de irrigação, em especial nas regiões com elevada concentração de áreas irrigadas, principalmente na época da seca (Costa, 1991).

Diversos programas públicos de irrigação foram implantados nas últimas décadas, visando difundir e incentivar esta tecnologia. Os programas assumiram papel relevante, no sentido de promover o desenvolvimento de diversas regiões do Brasil, principalmente das áridas e semi-áridas (Autran, 1984).

No norte de Minas Gerais, os projetos de irrigação vêm-se consolidando como importante alternativa na modernização e no crescimento da região. A aplicação de determinadas medidas, como a construção de pequenas barragens em locais estratégicos e a exploração de águas subterrâneas, tem contribuído para atenuar os danos causados pela carência de recursos hídricos na maior parte do ano.

Como a dependência da produção de áreas irrigadas aumenta a cada ano, a agricultura irrigada está enfrentando sérios desafios, que ameaçam sua sustentabilidade. De acordo com Gates et al. (1991) em muitas partes do mundo a água está-se tornando escassa. A competição pela demanda com os centros urbanos e industriais está impondo pressão sobre a agricultura irrigada, no sentido de promover melhoria na eficiência do uso da água.

Um dos principais problemas que ocorrem na agricultura, é a baixa eficiência com que são utilizados os recursos disponíveis. Uma produção eficiente e rentável deve constituir um dos principais objetivos da empresa agrícola. Para atingir este fim, deve-se utilizar racionalmente os fatores de produção, de tal maneira que sejam atingidos os mais altos níveis de produtividade econômica (Frizzone, 1995).

O agricultor, ao procurar otimizar a sua decisão deve escolher, dentre as alternativas de produção disponíveis, a mais eficiente na utilização dos recursos produtivos e a que satisfaz a certos objetivos preestabelecidos. Em situações onde a tomada de decisão está relacionada à alocação de recursos limitados, esta alocação é função da decisão e da racionalidade do agricultor que depende, por sua vez, de métodos eficientes que o auxiliem na otimização da sua decisão.

O objetivo do presente trabalho foi utilizar um modelo de programação linear, para se selecionar as culturas e os meses de plantio que proporcionem a maximização da renda do agricultor e da utilização de recursos hídricos no Perímetro Irrigado do Gorutuba.

\section{MATERIAL E MÉTODOS}

Para a utilização da técnica de programação linear foi proposto um modelo cuja função-objetivo visava maximizar as receitas mensais em função da área cultivada com determinadas culturas, tendo-se como restrições a área e a disponibilidade de água. Esquematicamente, o modelo pode ser representado pelas equações:

$$
\text { MAXRL }=\sum_{\mathrm{i}=1}^{\mathrm{NC}} \sum_{\mathrm{k}=1}^{12} \mathrm{R}_{\mathrm{ik}} \mathrm{A}_{\mathrm{ik}}
$$

ou

$$
\text { MAXRL }=\sum_{i=1}^{N C} \sum_{k=1}^{12}\left(P_{i k} \operatorname{Pr}_{i}-C_{i}\right) A_{i k}
$$

Tendo-se como restrições:

$$
\begin{gathered}
\sum_{\mathrm{i}=1}^{\mathrm{NC}} \mathrm{V}_{\mathrm{ik}} \mathrm{A}_{\mathrm{ik}} \leq \mathrm{VT}_{\mathrm{k}} \quad(\mathrm{k}=1, \ldots, 12) \\
\sum_{\mathrm{i}=1}^{\mathrm{NC}} \mathrm{A}_{\mathrm{ik}} \leq \mathrm{AT}_{\mathrm{k}} \quad(\mathrm{k}=1, \ldots, 12)
\end{gathered}
$$

em que:

MAX RL - maximização da receita líquida

I - número inteiro representando a cultura

$\mathrm{K}$ - número inteiro representando o mês do ano

$\mathrm{NC}$ - número de culturas consideradas

$\mathrm{R}_{\mathrm{ik}}$ - receita líquida proporcionada pela cultura i quando cultivada no mês $\mathrm{k}, \mathrm{R} \$ \mathrm{ha}^{-1}$

$\mathrm{A}_{\mathrm{ik}} \quad$ - área cultivada com a cultura i no mês $\mathrm{k}$, ha

$\mathrm{P}_{\mathrm{ik}} \quad$ - preço da cultura i, no mês $\mathrm{k}, \mathrm{R} \$ \mathrm{~kg}^{-1}$

$\mathrm{Pr}_{\mathrm{i}}$ - produtividade média da cultura $\mathrm{i}, \mathrm{kg} \mathrm{ha}^{-1}$

$\mathrm{C}_{\mathrm{i}}$ - média dos custos médios da cultura $\mathrm{i}$, incluindo a tarifa de água para irrigação, $\mathrm{R} \$$ ha $^{-1}$

$\mathrm{AT}_{\mathrm{k}}$ - área total irrigada em determinado lote, no mês $\mathrm{k}$, ha

$\mathrm{V}_{\mathrm{k}} \quad$ - volume de água utilizado com a cultura $\mathrm{i}$, em um determinado lote, no mês $\mathrm{k}, \mathrm{m}^{3}$ ha $^{-1}$ (considerando-se a eficiência de aplicação)

$\mathrm{VT}_{\mathrm{k}}$ - volume total da água disponível para o lote, no mês $\mathrm{k}$, $\mathrm{m}^{3}$.

As Eqs. 1 e 2 representam a função-objetivo a ser maximizada e as Eqs. 3 e 4, correspondem às restrições de volume de água e área, respectivamente.

O trabalho foi desenvolvido com os dados do Perímetro Irrigado do Gorutuba, que se localiza no município de Nova Porteirinha, norte do Estado de Minas Gerais. Com área total de 11.280 ha, o projeto Gorutuba se situa à jusante da barragem do Bico da Pedra, a partir da qual a água é conduzida por $127,5 \mathrm{~km}$ de canal. A rede de canais é dividida em 17 redes de acéquias, que abastecem 4.780 ha irrigáveis, localizados na margem direita do Rio Gorutuba (CODEVASF, 1996).

\section{Obtenção dos coeficientes da função-objetivo}

A fim de representar a área do Perímetro Irrigado do Gorutuba, foram selecionados nove lotes abastecidos pela acéquia A-5, cujas características são apresentadas na Tabela 1. Esta acéquia foi escolhida por apresentar: maior variedade de culturas implantadas; maior diversidade de características físico-hídricas dos solos, fazendo com que culturas cultivadas na mesma época necessitem de diferentes condições de manejo de irrigação; e maior área irrigada por aspersão entre as diferentes redes de acéquias, indicando maior flexibilidade na implantação de novas culturas. 
Tabela 1. Acéquia, área irrigável $\left(\mathrm{AT}_{\mathrm{k}}\right)$, em ha e sistemas de irrigação utilizados nos lotes selecionados para a execução do modelo de programação linear

\begin{tabular}{clcl}
\hline Lote & Acéquia & $\begin{array}{c}\text { Área } \\
\text { Irrigável }\end{array}$ & \multicolumn{1}{c}{ Sistemas de Irrigação } \\
\hline A* & A-5.7 & 38,0 & Sulco \\
B* & A-5 & 11,0 & Aspersão \\
C & A-5.1 & 8,46 & Aspersão \\
D & A-5.1 & 3,51 & Microaspersão \\
E & A-5.3 & 5,94 & Aspersão e microaspersão \\
F & A-5.5 & 2,95 & Sulco \\
G & A-5 & 8,16 & Aspersão \\
H & A-5 & 5,90 & Aspersão e microaspersão \\
I & A-5 & 7,97 & Sulco e aspersão \\
\hline * Lotes empresariais & & &
\end{tabular}

Para cada lote foi simulado o plantio de sete culturas que apresentavam a maior área cultivada na acéquia, sendo quatro anuais (feijão, milho, abóbora e quiabo) e três perenes (banana, variedades prata e nanica, manga e limão). O volume de água necessário para irrigação dessas culturas foi estimado considerando-se o fornecimento rotativo de água, em função da demanda evapotranspirométrica local, do tipo de solo e época de plantio para cada cultura, utilizando-se o software desenvolvido por Carvalho (1998).

$\mathrm{Na}$ Tabela 2 tem-se os preços dos produtos agrícolas, a produtividade e o custo de produção de cada produto, desconsiderando-se o custo da água, segundo informações da CODEVASF (1995) observados para o ano de 1996. Observando-se esta tabela, verifica-se que a oferta dos produtos variam ao longo do ano. Em função dessas ofertas, os meses de plantio foram então adotados considerando-se a duração média do ciclo de cada cultura anual, razão pela qual foram ponderados, como meses de plantio para o feijão, janeiro, fevereiro, março, abril, maio, julho, agosto, outubro e novembro, totalizando nove épocas diferentes; o mesmo foi feito para as outras três culturas anuais, obtendo-se um mês de plantio para a abóbora, sete para o milho e dois para o quiabo.

A fim de melhor se visualizar a variação das receitas líquidas, foi realizado, para cada mês ao longo do ciclo de cada cultura, um fluxo de caixa simples, considerando-se o preço do produto, a produtividade e o custo de produção, incluindo o preço da água em função do volume consumido. Para isso, distribuiu-se o preço do produto, a produtividade e o custo médio de produção proporcionalmente ao longo dos meses de plantio. Para aquelas culturas anuais cujo ciclo ultrapassou o ano de 1996, o fluxo de caixa foi acumulado no mês de dezembro, levando-se em consideração as parcelas de preço, produtividade e custos para os meses seguintes.

Para as culturas perenes foram considerados, ao invés do mês de plantio, os meses em que a cultura estivesse produzindo e o produto vendido ao preço apresentado na Tabela 2; desta maneira, não se estava buscando a área a ser plantada e, sim, a área que deveria estar produzindo em determinado mês e com determinada cultura. Como não foi considerada a duração do ciclo de cultura, a produtividade média adotada para cada mês foi inversamente proporcional ao preço observado na região naquele mês respeitando-se, desta forma, a lei da oferta e da procura.

Na obtenção dos custos totais de produção $\left(\mathrm{R} \$\right.$ ha $\left.^{-1}\right)$ para cada cultura, em diferentes épocas de plantio, além dos valores apresentados na Tabela 2 foi considerado, também, o valor da tarifa de água cobrado no perímetro em 1996, segundo informações do Distrito de Irrigação do Gorutuba (DIG). Para o cálculo da tarifa de água foram utilizados os valores de $\mathrm{R} \$ 4,84$ ha $^{-1}$ mês $^{-1}$ e $\mathrm{R} \$ 7,131.000 \mathrm{~m}^{-3}$, para os coeficientes $\mathrm{K}_{1}$ $\mathrm{e} \mathrm{K}_{2}$, respectivamente, conforme Silveira (1993).

Os coeficientes de receita líquida utilizados na Eq. 1, foram estimados subtraindo-se os custos médios dos retornos obtidos para cada cultura, em função da época de plantio, para todos os lotes considerados. Cada coeficiente representa um $\mathrm{R}_{\mathrm{ik}}$, ou seja, o retorno líquido esperado para a cultura $\mathrm{i}$, cultivada em determinado lote, quando plantada no mês $\mathrm{k}$.

\section{Obtenção dos coeficientes das funções de restrição}

$\mathrm{O}$ volume de água disponível para o lote $\mathrm{j}$, no mês $\mathrm{k}\left(\mathrm{VT}_{\mathrm{jk}}\right)$ foi considerado igual àquele fornecido para os lotes em cada mês ao longo do ano de $1996 \mathrm{e}$ a área total $\mathrm{AT}_{\mathrm{k}}$ foi ponderada como sendo a área irrigável de cada lote (Tabela 3) ou seja, a área máxima possível de ser ocupada com o cultivo, no lote estudado e no mês k.

Tabela 2. Preço dos produtos agrícolas $\left(\mathrm{R} \$ \mathrm{~kg}^{-1}\right)$, produtividade média $\left(\mathrm{kg} \mathrm{ha}^{-1}\right)$ e custos médios de produção $\left(\mathrm{R} \$ \mathrm{ha}^{-1}\right)$ para as culturas consideradas, no Perímetro Irrigado do Gorutuba, em 1996

\begin{tabular}{|c|c|c|c|c|c|c|c|c|}
\hline \multirow[t]{2}{*}{ Mêt } & Abóbora & Feijão & Milho & Quiabo & Banana Prata & Banana Nanica & Limão & Manga \\
\hline & \multicolumn{8}{|c|}{ Preço dos Produtos $\left(\mathrm{R} \$ \mathrm{~kg}^{-1}\right)$} \\
\hline Jan & & 0,662 & & & 0,401 & 0,084 & 0,307 & \\
\hline $\mathrm{Fev}$ & & 0,500 & 0,180 & \multirow[t]{2}{*}{0,400} & 0,484 & 0,085 & 0,188 & \\
\hline Mar & & & 0,154 & & 0,375 & 0,158 & 0,180 & \\
\hline Abr & & 0,750 & 0,148 & \multirow{9}{*}{0,455} & 0,404 & 0,126 & 0,180 & \\
\hline Mai & & 0,831 & 0,156 & & 0,431 & 0,091 & 0,364 & \\
\hline Jun & & 0,830 & & & 0,601 & 0,090 & & \\
\hline Jul & & 0,829 & 0,161 & & 0,592 & 0,092 & & \\
\hline Ago & & 0,756 & 0,164 & & 0,413 & 0,219 & 0,402 & 1,00 \\
\hline Set & & & & & 0,315 & 0,182 & 0,751 & \\
\hline Out & \multirow{3}{*}{0,200} & 0,818 & & & 0,214 & 0,269 & 0,751 & \\
\hline Nov & & 0,752 & 0,156 & & 0,215 & 0,158 & 0,384 & 0,294 \\
\hline Dez & & & & & 0,198 & 0,092 & 0,429 & 0,219 \\
\hline & \multicolumn{8}{|c|}{ Produtividade $\left(\mathrm{kg} \mathrm{ha}^{-1}\right)$} \\
\hline & 18.000 & 1.800 & 5.500 & 15.000 & 26.000 & 44.000 & 22.000 & 18.000 \\
\hline & \multicolumn{8}{|c|}{ Custo de Produção (R\$ ha $\left.{ }^{-1}\right)$} \\
\hline & 2674,20 & 965,00 & 651,50 & 3611,50 & 1951,5 & 2676,50 & 996,40 & 1615,90 \\
\hline
\end{tabular}


Tabela 3. Volumes mensais de água $\left(\mathrm{VT}_{\mathrm{k}}\right)$ em $1000 \mathrm{~m}^{3}$ e área total irrigável $\left(\mathrm{AT}_{\mathrm{k}}\right)$ em ha, para os lotes estudados ao longo do ano de 1996

\begin{tabular}{|c|c|c|c|c|c|c|c|c|c|}
\hline \multirow{2}{*}{$\begin{array}{l}\text { Lotes } \\
\text { Meses }\end{array}$} & $\mathrm{A}$ & $\mathrm{B}$ & $\mathrm{C}$ & $\mathrm{D}$ & $E$ & $\mathrm{~F}$ & $\mathrm{G}$ & $\mathrm{H}$ & $\mathrm{I}$ \\
\hline & \multicolumn{9}{|c|}{ Volumes mensais $\left(1000 \mathrm{~m}^{3}\right)$} \\
\hline Jan & 53,10 & 11,09 & 12,35 & 5,15 & 5,29 & 6,35 & 13,36 & 6,55 & 12,35 \\
\hline Fev & 85,82 & 17,42 & 8,86 & 17,93 & 8,91 & 9,34 & 17,82 & 7,88 & 17,82 \\
\hline Abr & 60,26 & 14,26 & 7,06 & 7,16 & 7,06 & 7,06 & 14,11 & 6,88 & 14,44 \\
\hline Mai & 88,02 & 17,42 & 8,78 & 8,78 & 17,68 & 8,78 & 17,93 & 8,68 & 15,92 \\
\hline Jun & 75,29 & 15,84 & 15,84 & 7,92 & 8,10 & 7,92 & 9,70 & 8,10 & 13,08 \\
\hline Set & 76,32 & 16,42 & 7,35 & 7,49 & 7,49 & 7,49 & 14,98 & 8,93 & 13,33 \\
\hline Out & 52,81 & 12,10 & 10,62 & 5,18 & 2,66 & 5,31 & 10,26 & 6,55 & 8,32 \\
\hline Nov & 19,08 & 4,32 & 3,96 & 1,98 & 1,80 & 1,99 & 3,96 & 2,59 & 2,31 \\
\hline Dez & 18,00 & 6,05 & 4,54 & 2,27 & 1,95 & 2,95 & 5,29 & 2,23 & 2,89 \\
\hline \multicolumn{10}{|c|}{ Área (ha) } \\
\hline
\end{tabular}

\section{Solução do problema de otimização}

Para se chegar à solução do problema foi utilizado o pacote computacional LINDO (Linear, Interactive and Discrete Optimizer) o qual resolve sistemas de equações lineares, utilizando o algoritmo simplex.

Na primeira análise não foi imposta nenhuma restrição com relação à área mínima e/ou área máxima a ser ocupada com determinada cultura, a fim de representar condições locais de mercado, consumo interno ou problemas regionais; entretanto, visando-se manter a tradição do perímetro de grande produtor de banana, foram inseridas restrições de área máxima para as culturas anuais mais rentáveis e, assim, o programa foi novamente executado, considerando-se restrições de área para as culturas da abóbora, feijão, milho e quiabo, iguais às percentagens de ocupação verificadas no perímetro no ano de 1996, as quais foram de $1,65 \%, 1,82 \%, 2,83 \%$ e $0,20 \%$, respectivamente.

\section{Análise de sensibilidade}

Para se verificar a sensibilidade dos lotes com relação às diferentes características de solo e sistemas de irrigação na otimização por programação linear, as equações de restrição foram alteradas, no sentido de padronizar a área irrigável dos lotes e os volumes de água fornecidos a cada mês; para isto, os arquivos correspondentes a cada um dos lotes foram alterados, adotando-se uma área hipotética de 10 ha e volumes mensais que correspondem, respectivamente, a uma área média e aos volumes médios mensais entre os lotes estudados.

Desta maneira, tentou-se analisar o comportamento de cada lote na distribuição percentual das áreas ocupadas por cultura em relação à área total, sem se restringir à área ocupada por ela.

\section{RESULTADOS E DISCUSSÃO}

Na Tabela 4 são apresentadas as áreas a serem cultivadas para cada cultura, entre as várias épocas de plantio, para todos

Tabela 4. Áreas possíveis de serem irrigadas $\left(\mathrm{A}_{\mathrm{ik}}\right)$, em ha, resultantes da otimização por programação linear, para todos os lotes estudados, sem se restringir à área cultivada

\begin{tabular}{|c|c|c|c|c|c|c|c|c|c|}
\hline Culturas * & $\overline{\mathrm{A}}$ & B & $\mathrm{C}$ & $\mathrm{D}$ & $E$ & $F$ & $\mathrm{G}$ & $\mathrm{H}$ & I \\
\hline Abóbora (6) & 0 & 0 & 0,12 & 0 & 0 & 0 & 0 & 0 & 0 \\
\hline Feijão (1) & 17,18 & 0 & 2,42 & 0 & 0 & 0 & 0 & 0 & 1,50 \\
\hline Feijão (2) & 0 & 0 & 0 & 0 & 0 & 0 & 0 & 0 & 0 \\
\hline Feijão (3) & 0 & 0 & 0 & 0 & 0 & 0 & 0 & 0 & 0 \\
\hline Feijão (4) & 0 & 0 & 0 & 0 & 0 & 0 & 0 & 0 & 0 \\
\hline Feijão (5) & 0 & 0 & 0 & 0 & 0 & 0 & 0 & 0 & 0 \\
\hline Feijão (7) & 0 & 0 & 0 & 0 & 0 & 0 & 0 & 0 & 0 \\
\hline Feijão (8) & 13,87 & 0,59 & 1,64 & 0 & 0,78 & 0,10 & 0 & 0,20 & 1,50 \\
\hline Feijão (10) & 0 & 0 & 0 & 0 & 0 & 0 & 0 & 0 & 0 \\
\hline Feijão (11) & 0 & 0 & 0 & 0 & 0 & 0 & 0 & 0 & 0 \\
\hline Milho (1) & 0 & 0 & 0 & 0 & 0 & 0 & 0 & 0 & 0 \\
\hline Milho (3) & 0 & 0 & 0 & 0 & 0 & 0 & 0 & 0 & 0 \\
\hline Milho (4) & 0 & 0 & 0 & 0 & 0 & 0 & 0 & 0 & 0 \\
\hline Milho (7) & 0 & 0 & 0 & 0 & 0 & 0 & 0 & 0 & 0 \\
\hline Milho (10) & 0 & 0 & 0 & 0 & 0 & 0 & 0 & 0 & 0 \\
\hline Milho (11) & 0 & 0 & 0 & 0 & 0 & 0 & 0 & 0 & 0 \\
\hline Milho (12) & 13,87 & 0,59 & 1,76 & 0 & 0,78 & 0,10 & 0 & 0,20 & 1,50 \\
\hline Quiabo (4) & 19,89 & 2,67 & 4,91 & 0 & 1,32 & 0,52 & 0 & 0,20 & 1,50 \\
\hline Quiabo (10) & 6,02 & 2,07 & 3,27 & 0 & 0,53 & 0,42 & 0 & 0 & 0 \\
\hline Banana prata & 18,11 & 8,32 & 3,42 & 3,50 & 4,62 & 2,43 & 8,20 & 3,09 & 6,50 \\
\hline Banana nanica & 0 & 0 & 0 & 0 & 0 & 0 & 0 & 0 & 0 \\
\hline Manga & 0 & 0 & 0 & 0 & 0 & 0 & 0 & 0 & 0 \\
\hline Limão & 0 & 0 & 0 & 0 & 0 & 0 & 0 & 2,61 & 0 \\
\hline Área irrigável & 38,0 & 11,0 & 8,5 & 3,5 & 5,9 & 3,0 & 8,2 & 5,9 & 8,0 \\
\hline
\end{tabular}


os lotes estudados, que maximizariam o retorno líquido do agricultor. Como descrito anteriormente, trabalhou-se com uma época de plantio para abóbora, nove para o feijão, sete para o milho e duas para o quiabo, além das culturas perenes.

Verifica-se, pela Tabela 4, que a banana prata apresenta-se, em todos os lotes, como uma boa opção de plantio, devido ao fato desta cultura apresentar o mais alto coeficiente de retorno entre as culturas perenes; além disso, alguns lotes apresentaram a opção do cultivo de abóbora e limão. Com relação ao feijão, sua área de plantio variou nos meses de janeiro e agosto, enquanto o quiabo não apresentou área cultivada para o plantio em abril, nos lotes D e G, nem para o plantio em outubro, nos lotes D, G, H e I; de maneira semelhante ao quiabo, a cultura do milho apresentou área cultivada apenas no mês de dezembro, com exceção dos lotes $\mathrm{D}$ e $\mathrm{G}$, em razão dos melhores coeficientes de retorno esperados para esses meses de plantio.

Em função da alta produtividade e da rentabilidade esperadas, principalmente para a cultura do quiabo, os resultados já apresentados sugerem ocupação excessiva de área com esta cultura, não refletindo a situação real de plantio e de demanda do produto, no Perímetro Gorutuba.

Na Tabela 5 são apresentas as áreas a serem cultivadas para cada cultura, entre as várias épocas de plantio, para todos os lotes estudados, quando se restringiu a área das culturas anuais, a fim de refletir as condições reais de plantio no perímetro do Gorutuba.

Com a restrição de $1,65,1,82,2,83$ e $0,20 \%$ na área cultivada imposta às culturas da abóbora, feijão, milho e quiabo, respectivamente, observa-se maior ocupação da área com as culturas da banana prata e limão, condição que se aproxima da realidade do perímetro no ano de 1996 . Com relação às culturas anuais, o plantio do feijão e do milho pode ser recomendado nos meses de abril e julho e, para o quiabo, áreas de plantio praticamente desconsideráveis foram obtidas em razão da pequena percentagem de ocupação, citada anteriormente.

\section{Receitas líquidas e volume de água otimizado}

As receitas líquidas obtidas na otimização, com e sem restrição de área por cultura, estão apresentadas na Tabela 6 , em que a maior diferença observada foi de $33,6 \%$ no lote $C$. Observando-se a Tabela 5 , verifica-se que dos 8,5 ha deste lote apenas 5,83 ha foram ocupados ao longo de todo o ano, indicando a menor ocupação entre os lotes estudados. Nos lotes empresariais, a redução da receita líquida chegou a 15,2\% e, para os demais, esta redução atingiu 10,2\%, em média. Podese observar, ainda, que as receitas obtidas para os lotes D e G não diferiram em razão da ocupação total desses lotes com banana prata na otimização, sem e com restrição de área cultivada.

Os valores de receitas líquidas apresentados na Tabela 6 , referem-se às combinações de culturas e épocas de plantio

Tabela 6. Receitas líquidas, em R $\$ 1.000,00$, e diferenças percentuais resultantes da otimização sem e com restrição de área irrigável para as culturas anuais, para cada lote estudado

\begin{tabular}{|c|c|c|c|}
\hline \multirow[b]{2}{*}{ Lotes } & \multicolumn{2}{|c|}{ Receitas Líquidas $(\mathrm{R} \$ 1.000,00)$} & \multirow{2}{*}{$\begin{array}{c}\text { Diferença } \\
(\%)\end{array}$} \\
\hline & $\begin{array}{c}\text { Sem Restrição } \\
\text { de Área }\end{array}$ & $\begin{array}{c}\text { Com Restrição } \\
\text { de Área }\end{array}$ & \\
\hline A & 202,520 & 169,954 & 16,1 \\
\hline B & 67,750 & 57,961 & 14,4 \\
\hline $\mathrm{C}$ & 46,506 & 30,896 & 33,6 \\
\hline $\mathrm{D}$ & 23,046 & 23,046 & 0,0 \\
\hline $\mathrm{E}$ & 35,919 & 30,954 & 13,8 \\
\hline $\mathrm{F}$ & 18,381 & 16,287 & 11,4 \\
\hline G & 53,503 & 53,503 & 0,0 \\
\hline $\mathrm{H}$ & 35,435 & 34,916 & 1,5 \\
\hline I & 48,065 & 42,653 & 11,3 \\
\hline
\end{tabular}

Tabela 5. Áreas possíveis de serem irrigadas $\left(\mathrm{A}_{\mathrm{ik}}\right)$, em ha, resultantes da otimização por programação linear, para os lotes estudados, com restrição de área cultivada

\begin{tabular}{lccccccccc}
\hline \multicolumn{1}{c}{ Culturas * } & $\mathrm{A}$ & $\mathrm{B}$ & $\mathrm{C}$ & $\mathrm{D}$ & $\mathrm{E}$ & $\mathrm{F}$ & $\mathrm{G}$ & $\mathrm{H}$ & $\mathrm{I}$ \\
\hline Abóbora (6) & 0,63 & 0,18 & 0,14 & 0 & 0,02 & 0,05 & 0 & 0,10 & 0,13 \\
Feijão (1) & 0 & 0 & 0 & 0 & 0 & 0 & 0 & 0 & 0 \\
Feijão (2) & 0 & 0 & 0 & 0 & 0 & 0 & 0 & 0 & 0 \\
Feijão (3) & 0 & 0 & 0 & 0 & 0 & 0 & 0 & 0 & 0 \\
Feijão (4) & 0 & 0,20 & 0,15 & 0 & 0,11 & 0,05 & 0 & 0,09 & 0,15 \\
Feijão (5) & 0 & 0 & 0 & 0 & 0 & 0 & 0 & 0 & 0 \\
Feijão (7) & 0,69 & 0 & 0 & 0 & 0 & 0 & 0 & 0,01 & 0 \\
Feijão (8) & 0 & 0 & 0 & 0 & 0 & 0 & 0 & 0 & 0 \\
Feijão (10) & 0 & 0 & 0 & 0 & 0 & 0 & 0 & 0 & 0 \\
Feijão (11) & 0 & 0 & 0 & 0 & 0 & 0 & 0 & 0 & 0 \\
Milho (1) & 0 & 0,31 & 0,24 & 0 & 0,17 & 0,08 & 0 & 0 & 0,22 \\
Milho (3) & 1,07 & 0 & 0 & 0 & 0 & 0 & 0 & 0,08 & 0 \\
Milho (4) & 0 & 0 & 0 & 0 & 0 & 0 & 0 & 0 & 0 \\
Milho (7) & 0 & 0 & 0 & 0 & 0 & 0 & 0 & 0 & 0 \\
Milho (10) & 0 & 0 & 0 & 0 & 0 & 0 & 0 & 0 & 0 \\
Milho (11) & 0 & 0,02 & 0,02 & 0 & 0,01 & 0,01 & 0 & 0,01 & 0,02 \\
Milho (12) & 0,08 & 0 & 0 & 0 & 0 & 0 & 0 & 0 & 0 \\
Quiabo (4) & 22,14 & 6,20 & 1,17 & 3,50 & 4,06 & 2,0 & 8,20 & 3,09 & 6,50 \\
Quiabo (10) & 0 & 0 & 0 & 0 & 0 & 0 & 0 & 0 & 0 \\
Banana prata & 0 & 0 & 0 & 0 & 0 & 0 & 0 & 0 & 0 \\
Banana nanica & 4,53 & 3,06 & 4,14 & 0 & 0,75 & 0,58 & 0 & 2,61 & 0 \\
Manga & 38,0 & 11,0 & 8,5 & 3,5 & 5,9 & 3,0 & 8,2 & 5,9 & 8,0 \\
Limão & & & & & & & & & \\
\hline Área irrigável & & & & & & & & & \\
\hline * Os números entre parêntesis após os nomes das culturas representam os meses de plantio das culturas anuais & & & & & & 0 \\
\end{tabular}


obtidas pelo modelo de programação linear proposto; portanto, não existe qualquer relação entre os valores apresentados nesta Tabela com os valores de receitas líquidas obtidas pelos agricultores no ano de 1996.

Na Tabela 7 tem-se o volume de água resultante da otimização com a programação linear, quando se restringiu a área para as culturas anuais, em todos os lotes estudados. Percebe-se que, em razão dos lotes apresentarem área, sistemas de irrigação e tipos de solos diferentes, os volumes de água apresentam-se bastante variados.

Analisando-se as Tabelas 3 e 7, observa-se que o volume de água derivado para os lotes sempre foi maior que o volume otimizado, exceto para o mês de novembro no lote I, em que esses valores foram iguais; logo, conclui-se que o sistema de distribuição de água não limita a escolha das culturas a serem implantadas no Perímetro Irrigado do Gorutuba. O fator limitante da otimização foi, portanto, o próprio coeficiente da funçãoobjetivo, correspondente aos dados de preço, produtividade e custo de cada cultura (Tabela 1) que favoreceu ou não o cultivo, em determinados meses.

$\mathrm{Na}$ Tabela 8 são apresentadas as percentagens de área cultivada em relação à área total, quando se adotou uma área hipotética de 10 ha e um volume médio mensal para cada lote, referente à média dos volumes derivados para cada lote, no ano de 1996; logo, as variações nas percentagens de área por cultura e as receitas líquidas obtidas são devidas aos diferentes tipos de solo e sistemas de irrigação. Vale lembrar que a soma das áreas ocupadas por cultura, resultantes da otimização da receita líquida do produtor, não ultrapassa a área total do lote, uma vez que a área total irrigável de cada lote $\left(\mathrm{AT}_{\mathrm{k}}\right)$ foi uma restrição no modelo de programação linear, conforme Eq. 4.

Analisando-se a Tabela 8, constata-se que os lotes A e F apresentaram-se de maneira semelhante quanto à distribuição das culturas. A banana prata, cultura mais rentável e mais exigente em água, ocupou uma área irrigável de 37,3 e 46,4\%, respectivamente, nos lotes A e F. Por serem irrigados por sistemas de irrigação por sulco, esses lotes apresentam maior demanda de irrigação, limitando a área irrigada com culturas mais exigentes, enquanto no lote I a banana ocupou $66,9 \%$ de área total irrigada, bem superior aos lotes A e F, devido, provavelmente, ao fato de parte desse lote ser irrigado por sulco e parte por aspersão, que proporciona melhor eficiência de aplicação, possibilitando maior ocupação da área com banana e, conseqüentemente, maior receita líquida.

Os demais lotes estudados apresentaram comportamento diferente dos lotes A, F e I. Por utilizarem sistemas de irrigação pressurizados, tem-se maior eficiência de aplicação, proporcionando maior área cultivada com banana prata e, em conseqüência, maior receita líquida.

Com relação ao tipo de solo, as disponibilidades totais de água (DTA) consideradas para os lotes A, F e I, foram de 2,12, 1,33 e 1,08 $\mathrm{mm}$ de água/cm de solo, respectivamente, para o lote B, 0,93 mm de água/cm de solo e, para o lotes C, D e E, a 1,33 mm de água/cm de solo; portanto, os resultados não permitem inferir sobre o efeito da disponibilidade de água sobre a área cultivada e a receita líquida. Este resultado é esperado para sistemas que trabalham com alta freqüência de irrigação, como é o caso do Projeto Gorutuba; pode-se concluir, então, que as diferenças entre a ocupação das áreas irrigadas e, conseqüentemente, entre as receitas observadas para esses lotes, foram mais influenciadas pelos sistemas de irrigação utilizados que pelas variações na DTA dos solos considerados.

\section{CONCLUSÕES}

1. Pelo modelo de programação linear proposto, verificou-se que a banana prata apresentou-se, em todos os lotes, como a melhor opção de plantio.

Tabela 7. Volumes mensais de água, em $1.000 \mathrm{~m}^{3}$, otimizados pela programação linear para os lotes estudados ao longo do ano de 1996

\begin{tabular}{|c|c|c|c|c|c|c|c|c|c|}
\hline \multirow{2}{*}{ Lotes } & \multicolumn{9}{|c|}{ Volume $-1.000 \mathrm{~m}^{3}$} \\
\hline & $\mathrm{A}$ & B & $\mathrm{C}$ & $\mathrm{D}$ & $\mathrm{E}$ & $\mathrm{F}$ & G & $\mathrm{H}$ & $\mathrm{I}$ \\
\hline Jan & 25,094 & 5,392 & 3,675 & 1,685 & 2,590 & 2,666 & 3,580 & 2,579 & 4,036 \\
\hline $\mathrm{Fev}$ & 65,057 & 12,179 & 6,420 & 4,305 & 6,118 & 6,079 & 11,471 & 7,173 & 10,361 \\
\hline Mar & 59,375 & 5,157 & 4,594 & 4,143 & 5,054 & 2,307 & 10,645 & 3,893 & 9,994 \\
\hline Abr & 22,680 & 11,307 & 5,540 & 4,110 & 5,877 & 5,758 & 11,340 & 6,347 & 10,293 \\
\hline Mai & 55,177 & 10,947 & 5,569 & 3,822 & 5,634 & 5,530 & 9,409 & 5,443 & 9,352 \\
\hline Jun & 43,656 & 8,671 & 4,539 & 2,977 & 4,404 & 4,366 & 8,424 & 4,955 & 7,568 \\
\hline Jul & 44,477 & 8,021 & 4,355 & 2,735 & 3,961 & 3,985 & 7,643 & 4,815 & 6,592 \\
\hline Ago & 48,983 & 9,252 & 5,056 & 2,944 & 4,296 & 4,373 & 6,593 & 4,640 & 7,210 \\
\hline Set & 38,842 & 7,131 & 4,892 & 1,968 & 3,126 & 3,322 & 5,730 & 4,763 & 4,813 \\
\hline Out & 29,187 & 6,566 & 5,258 & 1,517 & 2,634 & 2,935 & 4,216 & 4,400 & 3,733 \\
\hline Nov & 17,687 & 2,613 & 1,344 & 0,969 & 1,736 & 1,344 & 2,515 & 2,582 & 2,310 \\
\hline Dez & 7,072 & 1,755 & 1,147 & 0,421 & 0,686 & 0,722 & 1,036 & 1,077 & 1,004 \\
\hline
\end{tabular}

Tabela 8. Percentagens de área cultivada em relação à área total e receita líquida, em R\$, de cada lote, após a padronização da área e do volume mensal de água

\begin{tabular}{|c|c|c|c|c|c|c|c|c|c|}
\hline \multirow{2}{*}{ Culturas* } & \multicolumn{9}{|c|}{ Lotes } \\
\hline & A & $\mathrm{B}$ & $\mathrm{C}$ & $\mathrm{D}$ & E & F & $\mathrm{G}$ & $\mathrm{H}$ & I \\
\hline Feijão (1) & 50,7 & - & - & - & - & 32,0 & - & - & 6,9 \\
\hline Feijão (8) & 47,5 & - & - & - & - & 40,3 & - & - & - \\
\hline Quiabo (4) & 62,7 & - & - & - & - & 53,6 & - & - & 33,1 \\
\hline Quiabo(10) & 15,2 & - & - & - & - & 13,4 & - & - & 33,1 \\
\hline Banana Prata & 37,3 & 100,0 & 100,0 & 100,0 & 100,0 & 46,4 & 100,0 & 100,0 & 66,9 \\
\hline
\end{tabular}


2. Quando não se restringiu área de plantio, as melhores épocas de plantio são janeiro e agosto para o feijão, abril e outubro para o quiabo e dezembro para o milho.

3. Quando se restringiu a área de plantio no modelo de programação linear proposto, as melhores épocas de plantio do feijão e do milho foram os meses de abril e julho.

4. O volume de água derivado no ano de 1996 foi superior ao volume otimizado pela programação linear, quando a renda do produtor foi maximizada.

5. Sistema de distribuição de água não limita a escolha das culturas a serem implantadas no projeto Gorutuba.

6. A diferença entre a ocupação das áreas irrigadas e, conseqüentemente, entre as receitas líquidas observadas, é mais influenciada pelos sistemas de irrigação utilizados que pelas variações na capacidade de retenção de água dos solos considerados.

\section{REFERÊNCIAS BIBLIOGRÁFICAS}

AUTRAN, H.R.C. Planejamento agropecuário para o perímetro irrigado de Morada Nova, através de programação linear Estudo de caso para um lote típico. Fortaleza: Departamento Nacional de Obras Contra as Secas, 1984. 46p.
CARVALHO, D.F. Otimização do uso da água no perímetro irrigado do Gorutuba. Viçosa: UFV, 1998. 145p. Tese Doutorado

CODEVASF - COMPANHIA DE DESENVOLVIMENTO DO VALE DO SÃO FRANCISCO. Posição anual dos perímetros da 1ํㅗ․ BR. Brasília: CODEVASF, 1995.17p.

CODEVASF - COMPANHIA DE DESENVOLVIMENTO DO VALE DO SÃO FRANCISCO. Relatório anual do perímetro Gorutuba. Brasília: CODEVASF, 1996.49p.

COSTA, M.H. Modelo de otimização dos recursos hídricos para a irrigação, conforme a época de plantio. Viçosa: UFV, 1991. 111p. Dissertação Mestrado

FRIZZONE, J.A. Programação matemática aplicada a projetos hidroagrícolas. Viçosa, MG: Sociedade Brasileira de Engenharia Agrícola-SBEA. 1995. 29p.

GATES, T.K.; HEYDER, W.E.; FONTANE, D.G.; SALAS, J.D. Multicriterion strategic planning for improved irrigation delivery. I: Approach. Journal of Irrigation and Drainage Engineering, New York, v.117, n.6, p.897-913, 1991.

SILVEIRA, S.F.R. Análise econômica de agricultura irrigada: Projeto Jaíba. Viçosa: UFV, 1993. 145p. Dissertação Mestrado 